\title{
Palliative chemotherapy outcomes in patients with ECOG-PS higher than 1
}

\section{Rafael Caires-Lima, Karolina Cayres, Bruno Protásio, Inacelli Caires, Júlia Andrade, Lucila Rocha, Tiago Kenji Takahashi, Paulo M Hoff, Gilberto de Castro Jr and Milena Perez Mak}

Medical Oncology, Instituto do Cancer do Estado de Sao Paulo, Sao Paulo 01246-000, Brazil

This paper was presented at the American Society of Clinical Oncology (ASCO) Conference, in Chicago, 2013.

Correspondence to: Milena Perez Mak. Email: $\underline{\text { milena.mak@hc.fm.usp.br }}$

\begin{abstract}
Purpose: Although patients with incurable disease and Eastern Cooperative Oncology Group performance status (ECOG-PS $\geq 2$ ) are underrepresented in clinical trials, they are frequently offered palliative chemotherapy $(\mathrm{pCT})$ in daily clinical practice in order to improve symptoms and quality of life. In this case-control retrospective analysis, our goal was to identify factors associated with poorer survival and lack of benefit of pCT in this population.

Patients and methods: We evaluated 2,514 patients who died between August 2011 and July 2012 in an academic cancer care institution and its hospice. A total of 301 patients with solid tumours and ECOG-PS $\geq 2$ at prescription of pCT were selected for this case-control retrospective analysis. Cases were defined as patients who survived less than 90 days after the first cycle of first line pCT, and controls were those who had a longer survival.
\end{abstract}

Results: 142 cases and 159 controls were included. Cases were more likely to experience grade $\geq 3$ toxicity ( $43 \%$ versus $28 \% ; p=0.005$ ), die of toxicity $(16 \%$ versus $6 \% ; p<0.001)$ and not be offered best supportive care (BSC) only ( $47 \%$ versus $71 \% ; p<0.001)$. Median overall survival was 204 among controls and 34 days in cases (hazard ratio $=0.177 ; 95 \%$, confidence interval $=0.015-0.033, p<0.001$ ). Logistic regression analysis identified ECOG-PS $>2$ (odds ratio $(\mathrm{OR})=2.3, p=0.044$ ) and serum creatinine $(\mathrm{sCr})>1 \mathrm{mg} / \mathrm{dL}(\mathrm{OR}=11.2, p<0.001)$ as independent predictors of 90 -day mortality.

Conclusions: The independent predictors of short survival (less than 3 months) after initiation of pCT in this population were ECOG-PS > 2 and elevated sCr. Therefore, patient selection is crucial, as PCT may be deleterious in ECOG-PS $\geq 2$ pts.

Keywords: palliative chemotherapy, supportive care, prognosis, poor performance status, end-of-life care

Published: 30/04/2018

Received: 12/09/2017

ecancer 2018, 12:831 https://doi.org/10.3332/ecancer.2018.831

Copyright: $\odot$ the authors; licensee ecancermedicalscience. This is an Open Access article distributed under the terms of the Creative Commons Attribution License (http://creativecommons.org/licenses/by/3.0), which permits unrestricted use, distribution, and reproduction in any medium, provided the original work is properly cited. 


\section{Background}

Throughout the years, palliative chemotherapy $(\mathrm{pCT})$ has evolved and provided patients with metastatic cancer higher survival rates [2, 8]. In addition, improvement in supportive care and drug development have facilitated adverse events management and yielded better tolerance to chemotherapy. Hence, pCT has become the standard treatment for cancer patients with unresectable or metastatic disease. In this scenario, the main goals of treatment are to provide symptomatic relief as well as prolong survival with manageable toxicity in a number of diseases.

Previous studies have shown that the Eastern Cooperative Oncology Group performance status (ECOG-PS) is a powerful prognostic factor in patients submitted to pCT [10-12, 16, 19]. Poor performance status patients (ECOG-PS $\geq 2$ ) usually tolerate pCT poorly, with increased toxicity compared to patients with ECOG-PS $0-1[18,20]$. With few exceptions, this patient population is underrepresented in randomised clinical trials and the actual benefit of pCT in this setting in unknown. In this scenario, the choice of BSC can be an acceptable approach $[13,25]$. Besides, it should be emphasised that some reports have shown that early introduction of palliative care integrated to standard oncologic treatment reflected in improvement in quality of life, mood and survival [3, 21, 24].

In daily practice, however, unselected patients with ECOG-PS $\geq 2$ are often treated with pCT, as a tool to provide patients some gain in terms of symptom palliation and even a doubtful gain in survival [15]. Clinicians' estimates of patient's survival can be flawed and subjected to personal experience [6]. In order to improve such forecasting, numerous scores have been developed. However, most of these scores were validated in patient population under BSC alone [14, 22]. This underscores the need to identify clinical characteristics of poor performance status patients who derive benefit from $\mathrm{pCT}$, avoiding overtreatment and providing patients with the best palliative treatment.

The aim of this study was to identify prognostic factors associated with poorer survival and lack of benefit of pCT in this subset of patients.

\section{Materials and methods}

\section{Endpoints}

A case-control retrospective analysis was conducted. The primary endpoint was to identify prognostic factors associated with short overall survival (less than 3 months) in patients with unresectable or metastatic incurable solid tumours who presented ECOG-PS greater than or equal to two at the time of first line pCT. Secondary endpoints were to assess the percentage of patients with improvement in ECOG-PS after pCT, incidence of higher than grade 2 toxicity, time from the last day of pCT to death, percentage of patients referred for exclusive BSC, percentage of patients who died due to toxicity and to estimate the median overall survival in both case and control populations.

\section{Patient selection}

Three hundred and one consecutive patients with unresectable or metastatic solid tumours, who presented ECOG-PS greater than or equal to two at the beginning of first line chemotherapy, were identified from 2,514 patients who died between August 2011 and July 2012 in a public Brazilian tertiary cancer care institution (Instituto do Cancer do Estado de Sao Paulo) or its hospice.

Cases were defined as patients who survived less than 90 days after the first cycle of first line pCT, and controls were those who had a longer survival.

Exclusion criteria were patients who died during the same period, but received curative, neoadjuvant or adjuvant chemotherapy, tyrosine kinase inhibitor in first-line treatment, hormonal therapy or perioperative chemotherapy for liver metastasectomy. Patients with germ cell tumours were excluded from enrolment. Patients with missing data in their electronic medical records were also excluded.

\section{Data extraction and definitions of terms}

Data of eligible patients were collected from electronic medical records. All researchers involved were trained in order to provide uniform data extraction. Patients' characteristics analysed were age, sex, date of diagnosis, ECOG-PS at beginning of treatment, primary tumour 
site, weight loss more than $10 \%$, oedema, dyspnoea, pain requiring opioid, altered mental status, cardiovascular comorbidities, diabetes mellitus, dementia, use of enteral feeding, serum haemoglobin, creatinine, ionised calcium, albumin and c-reactive protein, previous admission and first cycle of $\mathrm{pCT}$ in-hospital. Overall survival was defined as time between the day of the first PCT cycle and death. Toxicities were graded based on National Cancer Institute-common terminology criteria for adverse events (NCI-CTC AE) version 4.03. All patients who underwent $\mathrm{PCT}$ also received BSC as part of their treatment.

\section{Statistical analysis}

Frequencies were compared by chi-square test or Fisher exact test. Risks were estimated by odds ratios (ORs) and logistic regression analysis to determine possible prognostic factors. Overall survival was calculated by Kaplan-Meier method and curves were compared using log-rank test. All analyses were performed by MedCalc (MedCalc, Mariakerk, Belgium), version 11.5.1.0 and SPSS version 18 (SPSS, Chicago, IL). This study was submitted and approved by the local Ethics Research Committee.

\section{Results}

In this analysis, 142 cases and 159 controls were included. Patients' characteristics are summarised in Table 1. Patients included as cases were slightly younger (58 versus 63 years, $p=0.09$ ). Gender was equal between both groups, with female patients frequency of $49 \%$ and $50 \%$ [ $p=$ not significant (NS)] in each group, respectively. Cases presented more frequently with ECOG-PS 3 or 4 when initiating PCT than controls ( $p=0.03$; chi-square). Gastrointestinal (31\%) and lung cancers $(17 \%)$ were the most frequent primary tumours in both groups $(p=0.077$; chi-square).

Significant adverse prognostic factors found in the univariate analysis included older age ( $>60$ years old, OR $=1.7 ; 95 \%$ confidence interval $(\mathrm{Cl})=1.0-2.6)$ and higher PS (ECOG $>2, \mathrm{OR}=1.9 ; 95 \% \mathrm{Cl}=1.2-3.1)$, as expected. As found in other reports [14,22], weight loss $>10 \%$ $(\mathrm{OR}=1.8 ; 95 \% \mathrm{Cl}=1.1-2.8)$, low haemoglobin $(\mathrm{OR}=2.6 ; 95 \% \mathrm{Cl}=1.6-4.2)$, low albumin $(\mathrm{OR}=2.7 ; 95 \% \mathrm{Cl}=1.5-5.1)$, high $\mathrm{C}$-reactive protein $(\mathrm{OR}=8.6 ; 95 \% \mathrm{Cl}=1.0-72.9)$, elevated serum creatinine $(\mathrm{sCr})(\mathrm{OR}=2.8 ; 95 \% \mathrm{Cl}=1.6-5.0)$, altered mental status $(\mathrm{OR}=4.2$; $95 \% \mathrm{Cl}=1.4-13.2)$ and in-hospital $\mathrm{pCT}(\mathrm{OR}=3.2 ; 95 \% \mathrm{Cl}=1.9-5.2)$ were also related to poor survival [5]. Curiously, diabetes mellitus $(\mathrm{OR}=0.41,95 \% \mathrm{Cl}=0.19-0.86)$ and cardiovascular comorbidities $(\mathrm{OR}=0.57, \mathrm{Cl}=0.35-0.91)$ were also associated with longer survival. Prognostic factors are given in Table 2.

Logistic regression analysis identified ECOG-PS $>2(\mathrm{OR}=2.3, p=0.044)$ and elevated $\mathrm{sCr}>1 \mathrm{mg} / \mathrm{dL}(\mathrm{OR}=11.2, p=0.0002)$ as independent prognostic factors of survival less than 3 months. Cardiovascular comorbidities also persisted as predictor of longer survival in this analysis $(\mathrm{OR}=0.34, p=0.0159)$ (Table 2$)$.

Analysing outcomes after pCT (Table 3), cases were more likely to experience grade three or more toxicity (43\% versus $28 \% ; p=0.005$ ). However, febrile neutropenia was not statistically different between groups $(11.3 \%$ versus $7.6 \% ; p=0.36)$. Controls had a more expressive improvement in ECOG-PS (27.2\% versus $1.41 \% ; p<0.0001)$. Cases experienced more toxic deaths $(16 \%$ versus $6 \% ; p=0.0007)$ and were less likely to be kept under BSC alone after failure of first line chemotherapy and beyond ( $47 \%$ versus $71 \% ; p<0.0001)$. More patients in case group also received $\mathrm{pCT}$ in their last month of life $(71.1 \%$ versus $12.6 \% ; p<0.0001)$, with a median time from last $\mathrm{pCT}$ to death of 22.5 days in cases and 76.5 days in the control group $(p<0.001)$.

Median overall survival was 34 and 204 days between cases and controls, respectively (hazard ratio $(\mathrm{HR})=0.177 ; 95 \% \mathrm{Cl}=0.015-0.033$, $p<0.0001)$ (Figure 1). For all patients, median overall survival was 99 days $(1-1207)$, demonstrating the poor prognosis of this population of poor-PS patients overall (Figure 2).

\section{Discussion}

In this study, we investigated the prognostic factors associated with poor survival after first line $\mathrm{pCT}$. We hypothesised that a survival shorter than 3 months after initiating first line pCT implies its lack of benefit and determining the factors associated with it could aid physicians to better select patients and avoid unnecessary toxicity. 
Table 1. Patients' characteristics.

\begin{tabular}{|c|c|c|c|}
\hline & Cases & Controls & $p$ value \\
\hline & $N=142(\%)$ & $N=159(\%)$ & $0.1-0.7 \mathrm{nM}$ \\
\hline Age (years) & & & 0.541 \\
\hline $18-40$ & $13(9.2)$ & $15(9.4)$ & \\
\hline $40-60$ & 59 (41.5) & 55 (34.6) & \\
\hline$>60$ & $70(49.3)$ & $89(56)$ & \\
\hline Median & $58(17-86)$ & 63 (18-87) & \\
\hline Sex & & & 0.850 \\
\hline Male & $73(51.4)$ & $80(50.3)$ & \\
\hline Female & $69(48.6)$ & $79(49.7)$ & \\
\hline ECOG-PS & & & 0.006 \\
\hline ECOG-2 & $67(47.2)$ & $101(63.5)$ & \\
\hline ECOG-3 & $65(45.8)$ & $56(35.2)$ & \\
\hline ECOG-4 & $10(7)$ & $2(1.3)$ & \\
\hline Primary & & & 0.016 \\
\hline \multicolumn{4}{|l|}{ Lung } \\
\hline NSCLC & $17(12)$ & $25(15.8)$ & \\
\hline SCLC & $6(4.2)$ & $5(3.1)$ & \\
\hline \multicolumn{4}{|l|}{ Gastrointestinal } \\
\hline $\begin{array}{l}\text { Oesophageal/ } \\
\text { stomach }\end{array}$ & $26(18.3)$ & $17(10.6)$ & \\
\hline $\begin{array}{l}\text { Pancreas/ } \\
\text { biliary/liver }\end{array}$ & $19(13.4)$ & $13(8.2)$ & \\
\hline Colorectal & $17(12)$ & $24(15.1)$ & \\
\hline $\begin{array}{l}\text { Other } \\
\text { gastrointestinal }\end{array}$ & $1(0.7)$ & $10(6.3)$ & \\
\hline Breast & $9(6.3)$ & $4(2.5)$ & \\
\hline Head and neck & $4(2.8)$ & $14(8.8)$ & \\
\hline Urinary & $9(6.3)$ & $15(9.4)$ & \\
\hline Gynaecological & $4(2.8)$ & $20(12.6)$ & \\
\hline Unknown primary & $10(7)$ & $5(3.1)$ & \\
\hline Others & $11(7.7)$ & $7(4.4)$ & \\
\hline $\begin{array}{l}\text { Metastatic at } \\
\text { diagnosis }\end{array}$ & $95(67)$ & $103(65)$ & 0.699 \\
\hline Weight loss $>10 \%$ & $80(56)$ & $68(43)$ & 0.031 \\
\hline Anaemia & $116(82)$ & $108(68)$ & 0.031 \\
\hline Hypoalbuminemia & $62(44)$ & $45(28)$ & 0.011 \\
\hline High CRP & $109(77)$ & $76(48)$ & $<0.001$ \\
\hline High creatinine & $42(30)$ & $20(13)$ & 0.001 \\
\hline
\end{tabular}


Table 1.Continued.

\begin{tabular}{|l|c|c|c|}
\hline Hypercalcaemia & $10(7)$ & $8(5)$ & 0.113 \\
\hline Oedema & $31(22)$ & $34(21)$ & 0.566 \\
\hline Dyspnoea & $39(28)$ & $35(22)$ & 0.273 \\
\hline Opioid use & $83(59)$ & $86(54)$ & 0.446 \\
\hline Altered mental status & $14(10)$ & $4(3)$ & 0.007 \\
\hline Previous admission & $55(39)$ & $62(39)$ & 0.963 \\
\hline Tube feeding & $21(15)$ & $19(12)$ & 0.499 \\
\hline CVD & $44(31)$ & $70(44)$ & 0.066 \\
\hline DM & $11(8)$ & $27(17)$ & 0.055 \\
\hline Dementia & - & $5(3)$ & 0.103 \\
\hline In-hospital CT & $68(48)$ & $36(23)$ & $<0.001$ \\
\hline
\end{tabular}

NSCLC $=$ non-small cell lung cancer; $\mathrm{SCLC}=$ small cell lung cancer; $\mathrm{CRP}=\mathrm{C}$-reactive protein; $\mathrm{CVD}$ = cardiovascular disease; $\mathrm{DM}=$ diabetes mellitus and $\mathrm{CT}=$ chemotherapy

Table 2. Prognostic factors (primary endpoint).

\begin{tabular}{|l|c|c|}
\hline & Univariate analysis OR (CI 95\%) & Logistic regression \\
\hline Age $>60$ years & $1.7(1.00-2.60)$ & $\mathrm{NS}$ \\
\hline ECOG $>2$ & $1.94(1.20-3.10)$ & OR $2.3(p=0.044)$ \\
\hline Weight loss $>10 \%$ & $1.8(1.10-2.80)$ & $\mathrm{NS}$ \\
\hline Haemoglobin $<10 \mathrm{~g} / \mathrm{dL}$ & $2.59(1.61-4.16)$ & $\mathrm{NS}$ \\
\hline Albumin $<3 \mathrm{~g} / \mathrm{dL} \mathrm{g} /$ & $2.72(1.45-5.11)$ & $\mathrm{NS}$ \\
\hline CRP $\geq 5 \mathrm{mg} / \mathrm{L}$ & $8.60(1.01-72.93)$ & $\mathrm{NS}$ \\
\hline Creatinine $>$ ULN & $2.86(1.58-5.17)$ & $\mathrm{OR} 11.2(p=0.0002)$ \\
\hline Creatinine clearance $<60 \mathrm{ml} / \mathrm{min}$ & $1.77(1.07-2.92)$ & $\mathrm{NS}$ \\
\hline Altered mental status & $4.23(1.36-13.19)$ & OR $=0.34, p=0.0159$ \\
\hline CVD & $0.57(0.35-0.91)$ & $\mathrm{NS}$ \\
\hline DM & $0.41(0.19-0.86)$ & $\mathrm{NS}$ \\
\hline In-hospital CT & $3.18(1.93-5.23)$ & $\mathrm{N}$ \\
\hline
\end{tabular}

CRP = C-reactive protein; ULN = upper level of normality; CVD = cardiovascular disease; $\mathrm{DM}=$ diabetes mellitus; $\mathrm{CT}=$ chemotherapy; NS = not significant

As we could see, age older than 60 years, ECOG-PS higher than 2, weight loss higher than 10\%, serum haemoglobin less than $10 \mathrm{~g} / \mathrm{dL}$, serum albumin less than $3 \mathrm{~g} / \mathrm{dL}$, sCr higher than $1 \mathrm{mg} / \mathrm{dL}$, serum C-reactive protein higher than $5 \mathrm{mg} / \mathrm{L}$, altered mental status and in-hospital first cycle of pCT were identified as prognostic factors in univariate analysis. However, only ECOG-PS > 2 and sCr higher than $1 \mathrm{mg} / \mathrm{dL}$ persisted after logistic regression.

Interestingly, hypercalcaemia, a known poor prognostic factor [17], was not found to be related to short survival in this specific population. A low prevalence was found $(7 \%)$, reflecting two possible scenarios: either CT-naïve patients who were not amenable for systemic treatment due to hypercalcaemia related symptoms or a late, final disease event. 
Table 3. Secondary endpoints.

\begin{tabular}{|l|c|c|c|}
\hline & Cases $\mathbf{N = 1 4 2}(\mathbf{\%})$ & Controls $\mathbf{N = 1 5 9}(\mathbf{\%})$ & $\boldsymbol{p}$ value \\
\hline Toxicity $>$ G2* & $43 \%$ & $\mathbf{2 8 \%}$ & 0.005 \\
\hline Febrile neutropenia & $11.3 \%$ & $7.6 \%$ & 0.360 \\
\hline Response rate & $10.6 \%$ & $41.3 \%$ & $<0.001$ \\
\hline Improved ECOG & $1.4 \%$ & $27.2 \%$ & $<0.001$ \\
\hline Referred to exclusive BSC & $47 \%$ & $71 \%$ & $<0.001$ \\
\hline Death due toxicity & $16 \%$ & $6 \%$ & $<0.001$ \\
\hline $\begin{array}{l}\text { Median time from last CT to } \\
\text { death (days) }\end{array}$ & $22.5(0-77)$ & $76.5(4-1103)$ & $<0.001$ \\
\hline CT in last month of life & $71.1 \%$ & $12.6 \%$ & $<0.001$ \\
\hline Median overall survival & 34 days & 204 days & $<0.001$ \\
\hline
\end{tabular}

*Toxicity graded by (NCl-CTC AE) version 4.0.

$\mathrm{BSC}=$ Best supportive care; $\mathrm{CT}=$ Chemotherapy

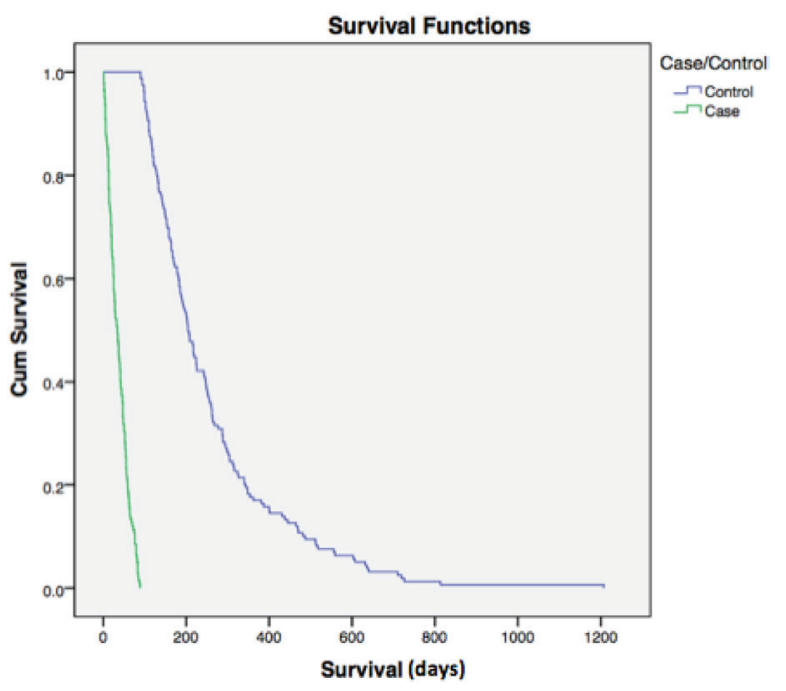

Figure 1. Overall survival case versus controls. Median overall survival was 34 and 204 days among cases and controls, respectively $(\mathrm{HR}=0.177 ; 95 \% \mathrm{Cl}=0.015-0.033, p<0.0001)$. Cum = cumulative .

Another unexpected finding was the association of cardiovascular comorbidity to longer overall survival. This could reflect the benefits of concomitant medications (statins, metformin and aspirin) usually administered to this patient population, which could represent bias of a retrospective study or collinearity effect in logistic regression analysis [1,4].

From all 2,514 patients who died in this period, those with ECOG-PS higher than one at the beginning of pCT who survived less than 3 months (cases) represented only $5.64 \%$. Only 124 patients (4.93\% of all cases) received the last dose of chemotherapy in their last month of life. This is within the acceptable threshold (10\%) for chemotherapy administration in the end-of-life [9].

Decision making towards continuity of chemotherapy treatment is influenced not only by clinical factors, but also by clinician's personal experience and patient preference [7]. However, administration of pCT in patients with poor prognosis can lead to delayed hospice referral, increased invasive procedures, such as mechanical ventilation, and lower likelihood of dying in the preferred place of death [23]. 


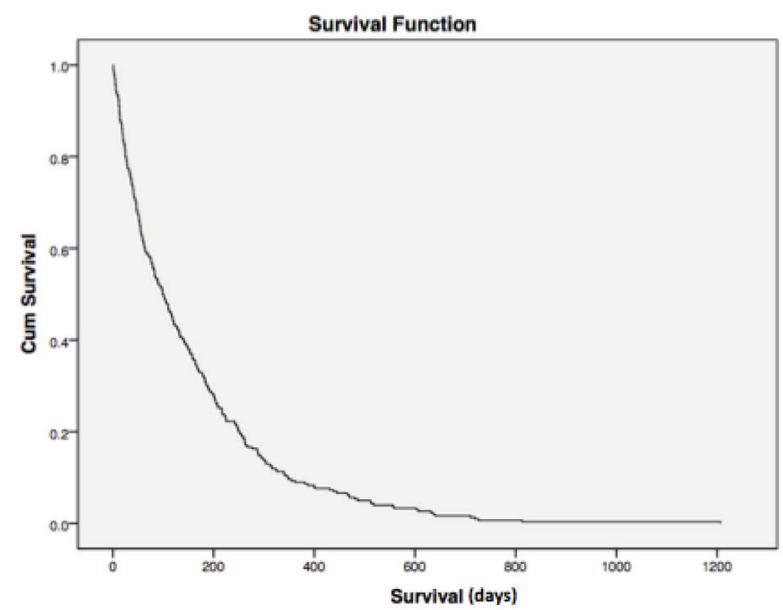

Figure 2. Overall survival. For all patients, median overall survival was 99 days (1-1207), demonstrating the poor prognosis of this population of poor-PS patients overall. Cum = cumulative.

\section{Conclusion}

According to our results, pCT needs to be prescribed with caution in patients with ECOG-PS greater than or equal to 2 , since it seems to offer no benefit in overall survival, as well as possibly worsen the quality and length of life. Here, we identified ECOG-PS $>2$ and elevated $\mathrm{sCr}$ as possible adverse prognostic factors, which, if present, should alert clinicians to avoid routine pCT administration.

\section{Acknowledgments}

This research did not receive any specific grant from funding agencies in the public, commercial, or not-for-profit sectors.

\section{Conflicts of interest}

The authors have no conflicts of interest to declare.

\section{References}

1. UK Prospective Diabetes Study Group (1998) Effect of intensive blood-glucose control with metformin on complications in overweight patients with type 2 diabetes (UKPDS 34). UK Prospective Diabetes Study (UKPDS) Group Lancet $352854-865$ https://doi.org/10.1016/S0140-6736(98)07037-8 PMID: $\underline{9742977}$

2. (2017) Cancer of Any Site - Cancer Stat Facts Seercancergov [https://seer.cancer.gov/statfacts/html/all.html] Date accessed: $26 / 07 / 17$ 
3. Bakitas MA, Tosteson TD, and Li Z, et al (2015) Early versus delayed initiation of concurrent palliative oncology care: patient outcomes in the ENABLE III randomized controlled trial J Clin Oncol 33 1438-1445 https://doi.org/10.1200/JC0.2014.58.6362 PMID: 25800768 PMCID: $\underline{4404422}$

4. Cannon $\mathrm{CP}$, Braunwald $\mathrm{E}$, and $\mathrm{McCabe} \mathrm{CH}$, et al (2004) Intensive versus moderate lipid lowering with statins after acute coronary syndromes N Engl J Med 350 1495-1504 https://doi.org/10.1056/NEJMoa040583 PMID: 15007110

5. Chen KW, Liu CJ, and Lu HJ, et al (2012) Evaluation of prognostic factors and the role of chemotherapy in unfavorable carcinoma of unknown primary site: a 10-year cohort study BMC Res Notes 570 https://doi.org/10.1186/1756-0500-5-70 PMID: $\underline{22280526}$ PMCID: $\underline{3331815}$

6. Christakis NA and Lamont EB (2000) Extent and determinants of error in doctors' prognoses in terminally ill patients: prospective cohort study BMJ 320 469-472 https://doi.org/10.1136/bmj.320.7233.469 PMID: 10678857 PMCID: 27288

7. Clarke G, Johnston $S$, and Corrie $P$, et al (2015) Withdrawal of anticancer therapy in advanced disease: a systematic literature review BMC Cancer 15892 https://doi.org/10.1186/s12885-015-1862-0 PMID: 26559912 PMCID: 4641339

8. DeVita VT and Chu E (2008) A history of cancer chemotherapy Cancer Res 68 8643-8653 https://doi.org/10.1158/0008-5472.CAN07-6611 PMID: 18974103

9. Earle CC, Neville BA, and Landrum MB, et al (2005) Evaluating claims-based indicators of the intensity of end-of-life cancer care Int J Qual Health Care 17 505-509 https://doi.org/10.1093/intqhc/mzi061 PMID: 15985505

10. Hwang JE, Kim HN, and Kim DE, et al (2012) First-line single-agent chemotherapy for patients with recurrent or metastatic gastric cancer with poor performance status Exp Ther Med 4 562-568 https://doi.org/10.3892/etm.2012.644 PMID: 23170106 PMCID: $\underline{3501373}$

11. odaira M, Takahashi S, and Yamada S, et al (2010) Bone metastasis and poor performance status are prognostic factors for survival of carcinoma of unknown primary site in patients treated with systematic chemotherapy Ann Oncol $211163-1167$ https://doi.org/10.1093/annonc/mdp583

12. Lanzotti VJ, Thomas DR, and Boyle LE, et al (1977) Survival with inoperable lung cancer: an integration of prognostic variables based on simple clinical criteria Cancer 39 303-313 PMID: 832246

13. Lilenbaum R, Axelrod R, and Thomas S, et al (2008) Randomized phase II trial of erlotinib or standard chemotherapy in patients with advanced non-small-cell lung cancer and a performance status of $2 \mathrm{~J} \mathrm{Clin} \mathrm{Oncol} 26$ 863-869 https://doi.org/10.1200/

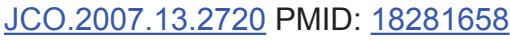

14. Maltoni M, Caraceni A, and Brunelli C, et al (2005) Prognostic factors in advanced cancer patients: evidence-based clinical recommendations--a study by the Steering Committee of the European Association for Palliative Care J Clin Oncol 23 6240-6248 https://doi.org/10.1200/JCO.2005.06.866 PMID: 16135490

15. Matsuyama R, Reddy S, and Smith TJ (2006) Why do patients choose chemotherapy near the end of life? A review of the perspective of those facing death from cancer J Clin Oncol 24 3490-3496 https://doi.org/10.1200/JCO.2005.03.6236 PMID: 16849766

16. Oken MM, Creech RH, and Tormey DC, et al (1982) Toxicity and response criteria of the Eastern Cooperative Oncology Group Am J Clin Oncol 5 649-655 https://doi.org/10.1097/00000421-198212000-00014 PMID: 7165009

17. Ramos REO, Mak MP, and Alves MFS, et al (2017) Malignancy-related hypercalcemia in advanced solid tumors: survival outcomes J Glob Oncol [doi:10.1200/JGO.2016.006890] https://doi.org/10.1200/JG0.2016.006890 PMID: 29244985 PMCID: $\underline{5735968}$

18. Reljic T, Kumar A, and Klocksieben FA, et al (2017) Treatment targeted at underlying disease versus palliative care in terminally ill patients: a systematic review BMJ Open 7 e014661 https://doi.org/10.1136/bmjopen-2016-014661 PMID: 28062473 PMCID: $\underline{5223692}$ 
19. Stanley KE (1980) Prognostic factors for survival in patients with inoperable lung cancer J Natl Cancer Inst 65 25-32 PMID: $\underline{6930515}$

20. Sweeney CJ, Zhu J, and Sandler AB, et al (2001) Outcome of patients with a performance status of 2 in Eastern Cooperative Oncology Group Study E1594: a Phase II trial in patients with metastatic nonsmall cell lung carcinoma Cancer 92 2639-2647 PMID: 11745199

21. Temel JS, Greer JA, and Muzikansky A, et al (2010) Early palliative care for patients with metastatic non-small-cell lung cancer N Engl J Med 363 733-742 https://doi.org/10.1056/NEJMoa1000678 PMID: 20818875

22. Vigano A, Dorgan M, and Buckingham J, et al (2000) Survival prediction in terminal cancer patients: a systematic review of the medical literature Palliat Med 14 363-374 https://doi.org/10.1191/026921600701536192 PMID: 11064783

23. Wright AA, Zhang B, and Keating NL, et al (2014) Associations between palliative chemotherapy and adult cancer patients' end of life care and place of death: prospective cohort study Bmj 348 g1219 PMID: 24594868 PMCID: 3942564

24. Zimmermann C, Swami N, and Krzyzanowska M, et al (2014) Early palliative care for patients with advanced cancer: a clusterrandomised controlled trial Lancet 383 1721-1730 https://doi.org/10.1016/S0140-6736(13)62416-2 PMID: 24559581

25. Zukin M, Barrios CH, and Pereira JR, et al (2013) Randomized phase III trial of single-agent pemetrexed versus carboplatin and pemetrexed in patients with advanced non-small-cell lung cancer and Eastern Cooperative Oncology Group performance status of $2 \mathrm{~J}$ Clin Oncol 31 2849-2853 https://doi.org/10.1200/JCO.2012.48.1911 PMID: 23775961 